\title{
Algumas Reflexões sobre Produção da Categoria de Gênero em Contextos como o Movimento Feminista e o Poder Judiciário
}

\author{
KARLA GALVÃO ADRIÃO • \\ SIMONE BECKER •
}

\section{RESUMO}

Pensando na discussão instaurada com a modernidade (em distintos contextos sociais), sobre a constituição dos sujeitos de direitos humanos universais, o presente trabalho buscará refletir sobre o indivíduo em sua interface com a busca de "cidadania" e do "acesso à justiça". Para tanto, analisaremos três casos concretos: duas conferências de Políticas para Mulheres, tidas aqui como rituais do movimento feminista no Brasil. Ambas dizem respeito à relação entre políticas para mulheres em duas perspectivas não-excludentes; uma delas entre as próprias mulheres - lésbicas, heterossexuais, brancas, negras, deficientes - e suas tensões direcionadas ora aos direitos individuais, ora aos direitos coletivos, num momento de discussão por cotas. A outra conferência aborda a tensão entre sexo e gênero, entre diferença como sinônimo de desigualdade. O terceiro caso retrata um julgamento de guarda e responsabilidade voltado à não-concessão da maternidade a uma mulher homossexual, mas seu deferimento ao pai tido como biológico. Por fim, sugerimos pensar como, nos dois contextos rituais distintos (Judiciário e Movimento Feminista), a categoria de gênero é produzida e se produz atrelada ao binômio biológico "macho e fêmea".

Palavras-chave: Direitos humanos; gênero; movimento feminista; Poder Judiciário.

Recebido em: 09/01/2006.

Aprovado em: 03/04/2006. 
O presente trabalho refere-se ao diálogo estabelecido entre duas pesquisas de doutoramento. Em ambas, buscar-se-á analisar como a diferença e os direitos constitucionais - cuja dualidade, a priori conciliável, emerge também com os feminismos e com a Constituição Federal de 1988 - em determinados casos concretos nem sempre dialogam entre si. Ou seja, como se colocam as tensões entre o princípio legal da supremacia do bem-estar comum num Estado de Direito Democrático e os direitos individuais (fundamentais) tomados como "personalíssimos e indisponíveis". Para tanto, de um lado, Galvão irá se debruçar sobre as conferências de Políticas para Mulheres (ocorridas em Santa Catarina e no Distrito Federal) e, de outro, Becker se centrará num processo de guarda e responsabilidade (Caçador/SC), envolvendo a disputa de uma criança, por parte de uma mulher estigmatizada como homossexual, aliado à produção doutrinária voltada à discussão da filiação "homoafetiva" no campo jurídico.

Iniciemos pelo campo de estudos sobre os feminismos no Brasil, para depois compreendermos os contextos das conferências para as mulheres que aqui serão analisadas. Comecemos caracterizando a diversidade do campo, constituído por diversas vertentes, e traçando a historicidade desse movimento no Brasil, tomando a década de 80 como ponto de partida.

Os anos 1980 constituíram uma experiência política das mais interessantes, porque as feministas brasileiras traçaram políticas de alianças com outras forças oposicionistas no processo de lutas pelas liberdades democráticas, sem abrir mão das especificidades de suas bandeiras de luta enquanto mulheres. Como consequiência, aumentaram o espaço político das feministas e seu poder reivindicatório. Um exemplo forte disto é a Constituição brasileira de 1988, uma das mais progressistas do mundo com respeito aos direitos da mulher na família e no trabalho (MORAES, 1996).

Ainda segundo Moraes (1996), fazendo referência aos anos 80 e relacionando-os à década anterior, talvez o sinal distintivo deste em relação ao feminismo brasileiro nos anos 70 tenha sido um grande comprometimento com a ação e intervenção - como demonstram as inúmeras passeatas e atos públicos encabeçados pelo movimento de mulheres, especialmente em São Paulo e Rio de Janeiro. Ao mesmo tempo em que traziam a bandeira da politização da vida privada, as feministas desenvolviam uma ampla política de alianças com setores mais progressivos e democráticos do país. ${ }^{1}$

A partir da década de 90, o campo de ações políticas e de estudos teóricos feministas e de gênero no Brasil se configura, tomando uma imbricação 
de vários espaços sociais, a saber: o campo dos grupos de estudos nas universidades, o campo das ONGs, o campo composto por mulheres que estão na gestão pública e o campo das redes ${ }^{2}$ e financiadoras, que também foram apropriadas por feministas que passaram a compor seus quadros de profissionais fixos. Esses movimentos se colocam num momento entre a anterior discussão sobre uma identidade feminista e feminina, calcada a partir da égide "nosso corpo nos pertence" e marcada nas lutas e discussões da condição local de cada mulher, passando para uma transnacionalização em que as discussões globais e, por conseguinte, a formação e consolidação de redes são de extrema importância para as políticas locais. ${ }^{3}$

Ainda na década de 90 têm início, com a passagem para estudos de gênero, pesquisas que buscam relacionar as questões de poder, tomando as mulheres em suas inter-relações com outras mulheres e com os homens, de maneira relacional. Este é um ponto introdutório que nos interessa aprofundar neste artigo, tendo em mente que discutimos uma das tensões heteronormativas que aparecem no seio desse movimento social: os lugares entre direitos individuais e direitos coletivos, tomando as noções de mulher e mulheres e as diversas configurações de especificidades femininas no feminismo. Assim, temos o início da discussão sobre políticas de cotas, que ressaltam desigualdades interconectadas: gênero e raça/etnia, gênero e geração, gênero e direitos sexuais, e as questões da heteronormatividade.

As Conferências de Políticas para Mulheres brasileiras surgem a partir da constituição dos novos campos de ação feminista, resultantes da compreensão dos contextos históricos envolvendo as décadas de 70, 80 e 90. A primeira Plataforma Política Feminista foi organizada por um grupo de entidades do movimento de mulheres nacional, tendo a Articulação de Mulheres Brasileira (AMB) como a grande impulsionadora nos estados brasileiros. Em 2002, ano de eleições presidenciais, essa articulação promoveu conferências municipais e estaduais em todo território nacional, com o intuito de construir uma plataforma norteadora das ações que as mulheres desejavam implementar via governos executivos. Em suma, trata-se de pontos que abordam micro e macropolíticas de acesso a direitos.

A segunda, a Conferência Nacional de Políticas para as Mulheres, constituída após dois anos de governo Lula, foi um empenho da Secretaria Especial de Políticas para as Mulheres, responsável pela orientação de um processo de conferências visando a constituir diretrizes que orientem políticas 
públicas voltadas às mulheres em todo território nacional. Um processo semelhante ao produzido junto às conferências municipais e estaduais.

De forma sucinta, ambas as conferências buscaram acesso dentro de uma agenda política feminista, que se orienta pelas três áreas prioritárias, a saber: saúde; direitos sexuais e reprodutivos; violência e participação feminina em espaços públicos. É sobre o segundo momento que nos debruçaremos neste texto, tomando o processo estadual - em Santa Catarina, Sul do Brasil - e o processo final em Brasília/DF, como um momento agregador das propostas estaduais e locais de todo o território nacional.

O processo/modelo dessas conferências surgiu nos moldes de outras conferências conhecidas, como as de saúde e educação, nas quais as mulheres já participavam tentando colocar suas demandas prioritárias em torno de questões específicas - por exemplo, a questão da mortalidade materna e do planejamento familiar, que, até então, eram discutidas apenas em conferências de saúde. Tal processo atravessou o território nacional, até chegar à fase final, na conferência nacional, em Brasília, em julho de 2004. ${ }^{4}$

Tomaremos aqui, para ilustrar a questão, uma das observações feitas por Karla Galvão na conferência estadual, em junho de 2004, mais especificamente sobre o momento em que as votações de decisões comuns foram tomadas. Vamos às anotações de campo da pesquisadora:

Um dos tópicos polêmicos apareceu quando se discutia sobre políticas de cotas. As mulheres negras, fortemente organizadas, colocavam-se sentadas na ala esquerda da plenária, olhando atentamente para a mesa de coordenação dos trabalhos. Mais ao centro, as lésbicas - ali representadas ela LBL-Sul (Liga Brasileira de Lésbicas - Região Sul) - se posicionavam e se confundiam com aquelas da secretaria do partido PC do B. Quando se falou em políticas de cotas, uma das mulheres pediu a palavra para dizer que, além das negras, havia que se prestar atenção e introduzir outras minorias. Ao passar de alguns segundos, uma grande polêmica se instalou com relação a quem constituía as minorias e quais direitos estas tinham em detrimento de outras mulheres ali presentes. Discutiu-se a real legitimidade das mesmas em terem direito a cotas e, paralelamente, também foram incluídas entre aquelas com direitos a cotas as indígenas e portadoras de deficiência. Então, uma segunda mulher coloca que aquelas que são lésbicas também deveriam ter acesso a cotas. Ao que outra pondera: "assim todas vão se dizer de orientação sexual lésbica para acessarem este direito", revelando a problemática da (in)visibilidade 
dessa identidade/categoria. Uma grande agitação se fez na plenária, e muitas mulheres começaram a perguntar: "o que restará para as heterossexuais, brancas e de camadas médias? Sim, pois se todas têm direito a cotas, quanto sobra de cotas neste total?".

Juntamente com a questão das cotas, gostaríamos de trazer também um outro momento, quando se votava a diretriz sobre licença-paternidade. A discussão também se tornou polêmica para muitas das mulheres, pois gostariam de pensar com cuidado (isto foi verbalizado pela mesa de coordenação da sessão: "Atenção, silêncio, muita atenção e cuidado com o que vamos votar agora") sobre por quanto tempo manteriam os homens em casa nos primeiros dias de nascimento do bebê. Homens estes que, segundo elas, poderiam mais atrapalhar do que ajudar.

A questão foi tratada como algo da ordem de uma possível heteronormatividade - tomando a heterossexualidade como norma -, colocando mulheres que cuidam de um lado e homens que atrapalham em outro, porém, também trazendo a possibilidade de uma relação com "novos homens, os nossos filhos, que foram criados por nós e que podem ajudar". Talvez aqui o que deva ser pensado é o próprio mito da maternidade alocado nas mulheres, algo que as feministas parecem que fizeram com a bandeira do "corpo nos pertence". Ou seja, uma relação de parceria e diálogo. ${ }^{5}$

Portanto, temos a tensão entre dois momentos, aparentemente distintos, que tratam da definição de regras para o cotidiano e acesso a cotas. As cotas se instalam num contínuo através do qual noções sobre a realidade social vão surgindo. Tentaremos enumerar algumas delas. Temos uma noção bastante marcada no contínuo de discussões feministas, que é a do lugar do homem nas escolhas e buscas de garantias das mulheres. Conseqüências são pensadas sobre como lidar com este outro e manter as garantias que as mulheres já conquistaram até então. Nesse rol podemos agregar todas as mulheres, unidas em torno de um espaço onde o contraponto é o homem.

Prosseguindo, uma segunda noção que surge aparentemente vem classificar - e por que não, separar, dividir em distintas identidades, que podem se coadunar - essas mulheres. São diferentes e, portanto, com necessidades particulares. Assim, as cotas surgem e fazem as mulheres refletirem desde dentro do movimento, caracterizando e lançando mão de noções que separem, diferenciem dentro do próprio fazer feminista. A política de cotas, neste sentido, 
parece afastar mais que a política de direito à licença-paternidade, já que a primeira trata de lançar mão, visível e demarcadamente, de diferenças e diferentes acessos a direitos dentro dos movimentos feministas - mulheres que se articulam em torno da conjunção de diferentes categorias (raça, orientação sexual, geração, deficiências, etc.), e não apenas em torno das desigualdades de gênero. Ou seja, existiam mulheres em um espaço comum, aqui são ressaltadas as necessidades individuais, porém de classes específicas.

Se tomarmos apenas uma noção que constitui o cotidiano de homens e mulheres e, assim, permeia os espaços dos movimentos feministas, podemos continuar nossa linha de raciocínio, pensando as relações entre igualdade de diferença. O termo escolhido é o da "heteronormatividade". Pode-se justificar a escolha deste termo, e não de outro, simplesmente por ele aparecer em ambos os exemplos do caderno de campo.

Nosso olhar que diferencia e iguala pessoas e objetos, classificando-os e etiquetando-os, se formula, primeiramente, se tomamos os estudos de gênero desde uma lógica binária na qual o sexo constitui e destitui lugares, poderes e subjetividades. Assim, a norma, o permitido, o comum em termos de ações sociais, parte de um modelo em que a heterossexualidade é a única possibilidade permitida. Mesmo sabendo que avanços sociais e em busca de acesso a direitos têm sido feitos, principalmente pautados pelos movimentos sociais, fato que nos faz refletir em que medida tal norma foi destituída de tanto poder legitimador. Entretanto, se tomamos os dois exemplos, percebemos como ela permanece perceptível e quase "inerente" ao olhar que dita regras numa conferência. Antes de avançarmos, lembremos: estamos analisando discursos (linguagens) que fazem parte de um espaço que busca constituir regras e diretrizes voltadas ao acesso a direitos. Portanto, trata-se de um momento especial, que pode nos auxiliar em nossas reflexões.

A noção de heteronormatividade é a mesma que vai ditar que homens e mulheres são diferentes e, portanto, constituem-se enquanto dois pólos de uma realidade social. Neste sentido, espera-se que as regras sobre a licençapaternidade sejam colocadas tomando as leis da reprodução como "naturalizadas" e os homens como "fracos aprendizes" desse lugar. Percebemos um aparente retorno à "lógica do instinto materno", através da qual os homens não seriam naturalmente dotados de possibilidades para o cuidado, vindo a atrapalhar. Mesmo que "novos homens" surjam, ainda paira o temor ao "homem que atrapalha mais do que ajuda". 
Ao mesmo tempo, quando falamos em políticas de cotas, estamos saindo de um lugar de igualdade dentro de uma categoria que agrega mulheres, para considerar as diferenças que constituem essas mesmas mulheres. E, neste lugar, as marcas que evidenciam as diferenças aparecem nos corpos de algumas mulheres, "naturalizando-as" mais uma vez. Nota-se nas questões raciais/ étnicas, de deficiência e de geração. Elas são palpáveis, estão na concretude do olhar que percebe. Porém as questões da ordem da sexualidade continuam (in)visíveis. Estão nos discursos que afirmam: somos lésbicas.

Portanto, o referido momento emblemático fala de uma busca por garantias de direitos - igualdade - alocada numa identidade ${ }^{6}$ de grupo. A tensão entre igualdade e diferença, na qual a igualdade une todas as mulheres em uma categoria mulher, é reforçada pela diferença com relação a um outro que, neste caso, é o homem (relação ainda marcadamente binária e dicotômica, tocada pelas diferenças sexuais). Por outro lado, denota a abertura para a constituição de uma categoria mulheres, na qual a diferença é demarcada dentro da categoria anterior, salientando as diversidades dentro de um mesmo espaço de constituição identitária, perpassado pela aparente supremacia da mulher branca, sem deficiências e heterossexual. Passemos agora para outro contexto analítico, ou ainda, para o mesmo, já que o contexto legal encontra-se imbricado com o jurisdicional.

A Constituição Federal (CF), nossa lei máxima promulgada e vigente desde 1988, é (re)conhecida tanto pela sua extensão (são mais de 200 artigos) quanto por sua referência exaustiva à proteção dos direitos individuais, sociais e coletivos. Todos esses convergem para o reforço de direitos fundamentais, tais como o direito à vida, à liberdade, à segurança, à igualdade e à propriedade (de cunho social, ao invés de patrimonial), baseados no princípio da dignidade humana.

Ao regrar, por exemplo, as relações de parentesco, a CF inova em relação às demais, ao conceder um capítulo à proteção "da família, da criança, do adolescente e do idoso" (BRASIL, 2005, p. 657-659). Todas essas prescrições culminaram na elaboração do Estatuto da Criança e do Adolescente (ECA-Lei $\mathrm{n}^{\circ}$ 8.069/1990 apud BRASIL, 2005) e do atual Código Civil Brasileiro (CCB Lei ${ }^{\circ} 10.406 / 2002$ ). Nas três legislações, a família, substantivo tratado no meio jurídico via de regra de forma singular, é entendida como aquela instituição formada a partir do casamento entre um homem e uma mulher, tendo (ou não) filhos - família nuclear. Além dessa previsão, considera-se ainda família como aquela união estável (ou concubinato) estabelecida entre um homem e uma 
mulher ou, simplesmente, como aquela formada a partir de um ascendente (pai ou mãe) e seus descendentes (ou filhos). Nas Constituições brasileiras anteriores (1946, 1967 e Emenda Constitucional no 1, de 1969), entendia-se como família aquela constituída a partir do casamento e, portanto, única apta "à proteção dos poderes públicos" (BRASIL, 1991, p. 533).

Em síntese, no Brasil não há quaisquer previsões legais expressas que assegurem direitos exclusivos aos homossexuais. Se, atualmente, algumas sentenças judiciais concedem a esses sujeitos sociais o que eles demandam no e do Judiciário, assim o são concedidos graças às interpretações feitas sobretudo pelos magistrados ditos avançados. Se, por um lado, são os juízes os efetivos detentores do "poder da caneta", determinando a obrigação de fazer ou deixar de fazer algo a alguém ou de dar ou deixar de dar algo a alguém, por outro, com auxílio de Michel Foucault (2001) e seus métodos genealógico/arqueológico, são os advogados aqueles que provocam o Judiciário com pedidos que não necessariamente apresentam resguardo legal. Ao juiz cabe esperar a demanda para julgar. Assim, se nos remetemos a Foucault é porque o poder circula e sobre ele não há o que se teorizar, apenas há o que se acompanhar: o seu lastro.

Mas se não há previsão legal expressa voltada aos homossexuais, como essa lógica concessiva de direitos à parentalidade (filiação e maternidade) ${ }^{7}$ se processa em nosso Poder Judiciário? E mais: constituir-se-iam esses direitos como distintos daqueles universais e heterossexuais veiculados pela legislação brasileira? Ao analisar apenas as sentenças proferidas pelos magistrados em diferentes processos (criminais, cíveis, etc.) brasileiros, observamos a presença de três discursos (estruturantes) distintos e por vezes complementares que são utilizados:

$1^{\circ}$ - os discursos legais, que são aqueles postos no papel, tidos como "letra morta" se não forem interpretados pelos juízes, promotores, dentre outros;

$2^{\circ}$ - os discursos jurisprudenciais, que são as reiteradas sentenças sobre uma mesma temática e, por fim;

$3^{\circ}$ - os discursos doutrinários, que são as interpretações legais constantes em artigos e livros, realizadas por diferentes operadores do Direito e que não necessariamente são utilizadas como bases para as sentenças.

Dessa forma, se não há previsão legal voltada à concessão de garantias aos homossexuais, há que se analisar caso a caso, levando-se em consideração os contextos (ou "procedimentos") externos e internos pertinentes aos próprios processos (FOUCAULT, 1994, 1999) que estão sob holofotes. Esses contextos 
externos ao discurso analisado são as memórias locais capazes de nos fazer constituir um "saber histórico das lutas e a utilização deste saber nas táticas atuais" (FOUCAULT, 2001, p. 171). Tal método Foucault denomina de genealógico. A diferença em relação ao método arqueológico, também foucaultiano, reside no objeto deste último, a saber: a arqueologia busca a compreensão do estabelecimento dos saberes, não no caráter evolutivo ("histórico") do termo, mas nietzschiano, na medida em que desconstrói as formas de conhecimento produtoras de verdades. Em suma, um não exclui o outro, por mais que neste ensaio estejamos muito mais propensas a utilizar o método arqueológico. Para tanto, faremos esse exercício tomando como objetos de análises (reflexões?) três artigos de Maria Berenice Dias ${ }^{8}$ e o único processo (recursal) de guarda julgado pelos Tribunais de Justiça da Região $\mathrm{Sul}^{9}$ - tendo uma mulher homossexual como parte envolvida na disputa, sob o n. 2002.008939-2.

Em suas palestras e produções escritas (incluindo seus julgamentos), Maria Berenice Dias toma o afeto como o argumento fundamental de suas análises. Um termo que consta no próprio ECA, ao definir em seu artigo 28, parágrafo $2^{\circ 10}$ o que se entende por "família substituta". Assim, nos artigos intitulados "Filiação homoafetiva" (DIAS, 2005a) e "A discriminação sob a ótica do Direito" (DIAS, 2005b), o afeto aparece como o denominador natural e universal da própria função "criativa" do Judiciário como supridor das lacunas do Legislativo. $\mathrm{O}$ fundamento legal para esse argumento encontra-se posto no princípio constitucional da dignidade humana. Passamos aos dizeres presentes no artigo "Filiação homoafetiva":

Mister reconhecer que é a presença de um elo de afetividade que gera uma entidade familiar a ser abrigada no Direito de Família. Desse conceito de família não podem ser excluídos os relacionamentos de pessoas do mesmo sexo, que, com a denominação de uniões homoafetivas, vêm sendo reconhecidas pela jurisprudência.

Não só a família, também a filiação foi alvo de profunda transformação. Das presunções legais de paternidade, chegou-se à plena liberdade de reconhecimento de filhos e à imprescritibilidade das ações para perquirir os vínculos de parentalidade. $O$ afeto é o elemento identificador das entidades familiares, $e$ é esse mesmo sentimento que serve de parâmetro para a definição dos vínculos parentais. A jurisprudência passou a atentar no melhor interesse da criança e a deferir a filiação a quem ela considera pai e que a ama como filha. 
Tal fez surgir uma nova figura jurídica, a filiação socioafetiva, que acabou se sobrepondo à realidade biológica (grifos nossos).

Complementamos com as proposições postas no artigo "A discriminação sob a ótica do Direito":

[...] A Constituição Federal do Brasil elegeu o respeito à dignidade humana como seu dogma maior, arrimado nos princípios da igualdade e liberdade.

A família consagrada pela lei - a sagrada família - é matrimonializada, patriarcal, patrimonializada, indissolúvel, hierarquizada e heterossexual. Pelas regras do Código Civil, os relacionamentos que fugissem ao molde legal, além de não adquirirem visibilidade, estavam sujeitos a severas sanções. Chamados de marginais, nunca foram os vínculos afetivos extramatrimoniais reconhecidos como família.

Em face das lacunas que acabam ocorrendo, o magistrado precisa se conscientizar de que as regras legais existentes não podem servir de limites à prestação jurisdicional. Quando o fato sub judice escapa da normatização ordinária, a resposta precisa ser encontrada nos direitos fundamentais que cada vez mais vêm buscando guarida nas Constituições. Não se trata de forma alternativa de se fazer justiça, mas de encontrar uma solução atendendo aos ditames de ordem constitucional.

Imperioso que as interpretações dos juizes sejam criativas (grifos nossos).

Em ambos os discursos observa-se que o afeto suplanta o biológico, produzindo-se como verdade legal e jurisdicional, detentora do condão de legitimar a produção do real: maternidade e filiação concretas. Julgar esses casos envolvendo homossexuais é, para a desembargadora, um ato criativo dos magistrados, justamente aqueles que deverão suprir o que a lei não fez e não faz. Detalhe: sob a ótica concessiva de direitos voltados à parentalidade (e ao parentesco) pleiteados por homossexuais, os magistrados são aconselhados pela jurista a não utilizarem outras leis que não digam respeito à temática, por mais afins que possam ser. Trata-se de criação pura, porém sublinhamos duas características vinculadas, pela desembargadora, ao ato criativo dos juízes:

$1^{\mathrm{a}}$ - a concessão de garantias matrimoniais estendidas aos homossexuais vincula-se, conforme o artigo "Um voto à homoafetividade", às leis regulamentadoras do "concubinato" (Leis nº 8.971/1994 e 9.278/1996); e 
$2^{a}$ - a justiça gaúcha pode ser tomada como precursora dessas inovadoras sentenças. Essa característica está presente no artigo "Um voto à homoafetividade" (DIAS, 2005c), tal como reproduzimos:

As uniões homossexuais, ao baterem nas portas do Judiciário, sempre as encontraram fechadas, principalmente as das Varas de Família. A justiça gaúcha foi a primeira a reconhecer as uniões entre pessoas do mesmo sexo como entidade familiar. Na ausência de lei que as regulamente, invoca-se a legislação que rege a união estável. Com isso os parceiros passaram a ter até direito à herança.

Em outros estados a forma encontrada para solver conflitos envolvendo uniões homossexuais é identificá-las como sociedade de fato. Com isso, além de ser negada a existência da afetividade na origem da relação, também se afasta seu caráter familiar. Tratada a união como sociedade comercial com fins lucrativos, os parceiros são considerados como se fossem sócios e, na dissolução da tal sociedade, tudo termina em mera divisão de lucros, assim considerados os bens amealhados durante o convívio, devendo cada sócio provar o quanto contribuiu para a formação do acervo social (grifos nossos).

No momento nos deteremos à última característica, retomando a primeira ao término deste item: utilização das leis do concubinato para criar os julgamentos de reconhecimento de parentalidade aos homossexuais.

Ao destacar a criatividade da justiça gaúcha em contraposição ao positivismo - pura aplicação da lei ao caso concreto praticado pelos demais estados, Dias distingue entre o universo jurídico gaúcho e as outras "jurisdições". Talvez não seja gratuitamente, pois a justiça gaúcha (aliada à catarinense) foi o berço do movimento conhecido no universo jurídico como Direito Alternativo, emergente na década de 90. De maneira sintética, pode-se dizer que o mencionado movimento surgiu na Região Sul (especialmente Florianópolis/SC e Porto Alegre/RS) após reportagem veiculada pelo Jornal da Tarde (São Paulo) com a manchete: "Juízes gaúchos colocam direito acima da lei".

A partir desse episódio, que objetivou, segundo estudiosos, a desmoralização de um grupo de juízes que se reuniam para estudar, ocorreu em Florianópolis, em setembro de 1991, o I Encontro Internacional de Direito Alternativo. Conforme Lédio Rosa de Andrade (2005), tal movimento denunciava especialmente "representar, o formalismo jurídico, uma forma de escamotear o 
conteúdo perverso de parte da legislação e de sua aplicação no seio da sociedade", sem que para tanto os positivistas evidenciassem a incompletude e incoerência existentes no Direito, face às suas inúmeras contradições e lacunas.

Assim, os juízes alternativos propunham, dentre outras questões: o uso alternativo do Direito como uma atividade hermenêutica, isto é, materializada através de uma "exegese extensiva de todos os textos legais com cunho popular e uma interpretação restrita das leis que privilegiam as classes privilegiadas" (ANDRADE, 2005). Em suma, a supremacia da Constituição Federal, somada à interpretação diversa daquela realizada pela maioria dos juízes que privilegia(va)m determinadas classes sociais. Sugerimos a retenção de tais peculiaridades para posterior análise, realizada junto com a decisão do único recurso existente na Região Sul atinente à temática da parentalidade (maternidade) homossexual. Passamos à sua descrição.

Trata-se de um recurso conhecido por "agravo de instrumento" promovido pelo advogado de Vera" ${ }^{11}$ contra a decisão do "juiz monocrático" de Caçador/SC, que concedeu a José - "pai biológico" - a guarda provisória de Marina. Resumidamente, Vera, desde a morte de sua "amiga" Maria, mantinha sob os seus cuidados a filha da falecida - Marina. Assim, ingressara com a ação - pedido - de guarda e responsabilidade da criança de oito anos, com o intuito de formalizar uma situação de fato. Ledo engano, pois a primeira decisão deferiu a guarda provisória de Marina a José, não obstante Vera ter afirmado provar ao longo do processo tanto a ausência de cuidados do pai em relação à filha (não-pagamento de pensão alimentícia, visitas não-regulares, etc. $)^{12}$ quanto o ato discriminatório do juiz monocrático, de ter-se influenciado pela imputação a ela feita no processo de ser uma "homossexual".

Dessa forma, coube ao TJSC o julgamento desta decisão provisória, proferida nos seguintes termos:

Relatório:

[...] Exasperada com a decisão, entendeu que o Juiz deu crédito a uma intriga sórdida, em que a agravante é colocada na condição de homossexual, pois, conforme consta das fls. 79/87, quer o agravado fazer crer, com as declarações que juntou, que a agravante é dada à prática do lesbianismo, na condição de amante da mãe da criança cuja guarda pretende. Daí haver destacado que o Magistrado teria ferido o art. $3^{\circ}$, inciso IV, da CF, ao tratá-la com discriminação, quanto à sua opção sexual. 
Voto:

[...] não se pode deixar de dizer que entre os altos interesses da menor está, sem sombra de dúvida, a preservação ou o refazimento de seus laços familiares ou parentais, tudo devendo ser feito para que o descendente menor, mormente no verdor dos anos, resgate o afeto e o carinho do pai biológico. E não é porque a criança nutre amor ou afeição pela agravante, pela boa convivência que têm, que a ela - e somente a ela - reservem-se o amor e os poderes da guarda da infanta.

[...] Modernamente, o direito de família evoluiu para permitir a chamada guarda compartilhada dos filhos menores, que melhor preserva, não apenas os laços entre os pais separados e sua prole, mas reparte por igual os poderes decorrentes do pátrio poder, pondo fim à interminável discussão de com quem deve ficar tal poder, se com a mãe ou o pai. Ora, no caso, ainda que a decisão provisória não tenha deferido à agravante todos os poderes defluentes do pátrio poder, defere-lhe, contudo, direitos que se aninham no seio de tal poder, conferindo-lhe prerrogativas especiais, para não permitir que perca ela contato com a criança que já lhe tem afeição filial.

Decisão:

Nos termos do voto do relator, conheceram do recurso e negaram-lhe provimento.

Participou do julgamento o Exmo. Sr. Des. Jorge Schaefer Martins. Pela douta Procuradoria-Geral de Justiça lavrou parecer o Exmo. Sr. Dr. Antônio Gercino Ramos de Medeiros.

Florianópolis, 8 de agosto de 2002.

MAZONI FERREIRA

Presidente com voto

LUIZ CARLOS FREYESLEBEN

Relator (grifos nossos).

Novamente o "afeto" é resgatado como argumento, apesar de decorrente do "biológico". Note-se que mesmo negando a guarda para Vera, o desembargador relator Luiz Carlos Freyesdeben não deixou de considerá-la como mãe social, ao dar-lhe o direito de visitas - "guarda compartilhada", tal 
como se concede a qualquer "cônjuge" que não fica com a guarda dos filhos havidos durante o casamento após o processo de separação. Assim, num primeiro momento de análise, pode-se aproximar a perda de Vera à pesquisa desenvolvida por Marilyn Strathern (1985), na qual médicos europeus nega(ra)mse a realizar inseminação artificial em mulheres virgens frente à ausência do intercurso sexual das mães com homens. A análise de Strathern mostra como, apesar de a sociedade americana e ocidental se encontrar norteada pelos princípios cristãos do nascimento virgem de Jesus Cristo, a influência ocidental fundante das noções de família nuclear e de maternidade (mulher/mãe) se pauta na necessidade do intercurso sexual entre um homem e uma mulher.

Entretanto, tal correlação se caracteriza como apressada se nos ativermos à conquista de Vera no tocante ao direito de visitas. Se, de um lado, os desembargadores negaram a guarda a Vera com base no vínculo entre biológico e afeto conjugados por José, de outro, o argumento pautado na universalização do afeto, tal como preconizado por Maria Berenice Dias, garantiu à amiga homossexual de Maria o direito cedido a quaisquer separandos heterossexuais em processos de separação e/ou divórcio. ${ }^{13}$

$\mathrm{Na}$ decisão final do recurso de agravo, houve uma conquista pautada naquela mesma característica ligada por Dias à pura função criativa dos magistrados, a saber: utilização de normas expressas voltadas seja ao concubinato, seja ao casamento civil, para julgar demandas de parentalidade e parentesco envolvendo homossexuais. Voltamos à questão anunciada anteriormente no presente ensaio: constituir-se-iam esses direitos como distintos daqueles universais e heterossexuais veiculados pela legislação brasileira?

Para traçar alguns caminhos rumo a possíveis respostas para esse problema, consideramos o afeto/amor em ambos os discursos - TJSC e de Maria Berenice Dias - como um fato social total (MAUSS, 2003), esteja ele afastado ou atrelado ao biológico. Assim o fazemos por dois motivos:

$1^{\circ}$ - o afeto em todos os discursos jurídicos voltados atualmente às polêmicas da parentalidade - ora calcada no afeto, ora no biológico (ver pesquisa de Fonseca, 2004) - mostra sua capilaridade em diferentes espaços, não se restringindo apenas ao campo jurídico; e

$2^{\circ}$ - apesar do paradoxo existente entre os argumentos do afeto alocado na natureza e/ou na cultura, observa-se que o mesmo culmina em decisões 
anunciadas como inovadoras, mas amparadas em modelos jurídicos de família, de parentalidade e de parentesco eminentemente heterossexuais.

Inspirando-nos nas análises de Foucault (1999), acerca da tensão existente entre o modelo do Panóptico de Bentham e as teorias penais de Beccaria, bem como nas desenvolvidas por Roberto da Matta (1981), em relação à fábula das três raças ou o problema do racismo à brasileira, sugerimos pensar que as práticas jurídicas aqui destacadas - independentemente das distintas correntes interpretativas - incluem as demandas de parentalidade advindas de homossexuais, para em ato contínuo excluir esses mesmos indivíduos de quaisquer outras garantias voltadas à família e ao parentesco distintas das universais postas em lei. Os direitos garantidos aos homossexuais são aqueles reificadores da heterossexualidade ${ }^{14}$ como regra. No plano legal, a exclusão das minorias (homossexuais em especial) está estampada expressamente, seja na CF, no ECA ou no atual CCB. Eis a diferença.

O Judiciário, ao julgar esses processos, por mais revolucionário que se poste, acaba por realimentar a lógica heterossexual. ${ }^{15}$ Para além das tensões existentes entre os poderes Judiciário e Legislativo, ${ }^{16}$ e entre os próprios operadores do Direito, nota-se a convergência de todas essas distintas esferas (onde circulam o poder) para certos princípios universalizantes de nossa sociedade.

Chegamos, portanto, ao grande problema de compatibilização entre as garantias individualistas (universais) e o reconhecimento das diferenças no bojo não apenas do plano legal ou das práticas dos operadores do Direito, ${ }^{17}$ mas das próprias tensões internas do movimento social. Ou ainda, ao retomarmos as duas tensões pontuais expostas no interior das Conferências de Políticas para Mulheres, vê-se a necessidade de analisarmos ou esmiuçarmos o(s) ethos no(s) qual(is) os Movimentos Feministas e os Poderes Judiciários (etc.) se encontram imersos. Assim, se determinados espaços sociais se produzem sobre (e sob) valores individualistas, a pluralidade dos próprios sujeitos se torna questionável, acima de tudo no que toca à sua própria produção e legitimação.

Aparentemente, pela própria constituição dos movimentos feministas no Brasil, tendemos a produzir uma imagem preconcebida de distanciamento entre Poder Judiciário, aquele dito poder reificador de conservadorismos e os movimentos sociais, combatentes constantes dessas normatividades, aquém da realidade social. Por fim, acreditamos ser necessário questionar a própria eleição de normas, desde dentro. Isto é, quais são as normatividades e então patologias 
que elegemos e reificamos nos distintos campos sociais e, então, de saber e poder, numa época da história e da filosofia do mundo ocidental em que estão sendo radicalmente questionadas nossas percepções adquiridas sobre o sujeito (BRAIDOTTI, 1989)?

\section{Referências}

ANDRADE, Lédio Rosa de. O que é Direito Alternativo. Revista Quaestio Iuris. Disponível em: www.uerj.br. 2005

Bohannan, Paul. A categoria injô na Sociedade Tiv". In: DAVIS (Org.). Antropologia do Direito: estudo comparativo de categorias de dívida e contrato. Rio de Janeiro: Zahar, 1983

BUTLER, Judith. Problemas de gênero: feminismo e subversão da identidade. Rio de Janeiro: Civilização Brasileira, 2003. (Série Sujeito e História)

. Variações sobre sexo e gênero. Beavouir, Wittig e Foucault. In: BENHABIB; CORNELL (Orgs.). Feminismo como crítica da modernidade. Rio de Janeiro: Rosa dos Tempos, 1987.

BRAIDOTTI, Rosi. A política da diferença ontológica. In: BRENNAN, Teresa (Org.). Para além do falo: uma crítica. São Paulo,l 1989.

BRASIL. Código Civil Brasileiro. 56 ${ }^{\mathrm{a}}$ Edição. São Paulo: Saraiva, 2005.

BRASIL. Constituição. Constituição da República Federativa do Brasil. Brasília: Senado Federal,1991.

Becker, Simone; GALVÃO, Karla. Le feminisme et le judiciaire au Brésil. In: CONGRES INTERNATIONAL DES RECHERCHES FEMINISTES DANS LA FRANCOPHONIE PLURIELLE. 4., Citoyennes sans frontières. Anais...Université d'Ottawa, Canada. 5-10 juillet, 2005.

CABRUJA, Teresa. Discursos sobre la 'diferencia': subjetividades supuestas, subjetividades impuestas y subjetividades somadas". (Texto apresentado na Conferencia internacional de Psicologia. 1999).

DA MATTA, Roberto. Digressão: a fábula das três raças, ou o problema do racismo à brasileira". In: . Relativizando: uma introdução à antropologia social. Petrópolis: Vozes, 1981. 
DIAS, Maria Berenice. Filiação homoafetiva. Disponível em: www.mariaberenicedias.com.br. Acessado em: maio 2005a.

. A discriminação sob a ótica do Direito. Disponível em: www.mariaberenicedias.com.br. Acessado em maio 2005b.

- Um voto a favor da homoafetividade. Disponível em: www.mariaberenicedias.com.br. Acessado em maio 2005c.

FONSECA, Cláudia. Caminhos da adoção. São Paulo: Cortez, 1995.

A certeza que pariu a dúvida: paternidade e DNA. Revista de Estudos Feministas, v. 12, n. 2, 2004.

FOUCAULT, Michel. História da sexualidade: a vontade de saber. Rio de Janeiro: Graal, 1988. v. 1.

. A vontade de saber. Rio de Janeiro: Zahar, 1989.

. Le sujet et le pouvoir. In: . Dits et écrits IV. Paris: Galimard, 1994. p. 222-243.

. A verdade e as formas jurídicas. Rio de Janeiro: NAU, 1999. . A microfísica do poder. Rio de Janeiro: Graal, 2001.

GLUCKMAN, Max. Obrigação e dívida. In: DAVIS (Org.). Antropologia do Direito: estudo comparativo de categorias de dívida e contrato. Rio de Janeiro: Zahar, 1973.

HEILBORN, Maria L. Dois é par: Gênero e identidade sexual em contexto igualitário. Rio de Janeiro: Garamond Universitária, 2004.

MAUSS, Marcel. Ensaio sobre a dádiva. In: MAUSS, Marcel. Sociologia e antropologia. São Paulo: Cosac \& Naif, 2003.

MORAES, Maria Lígia de. Marxismo e feminismo no Brasil. Primeira versão, n. 66, IFCH/UNICAMP, 1996.

RUBIN, Gayle. El trafico de mujeres: notas sobre la economia politica del sexo. Nueva Antropologia, v. 8, n. 30, 1986.

SPLENGLER, Fabiana Marion. União homoafetiva: o fim do preconceito. Santa Cruz do Sul: Edunisc, 2003. 
STRATHERN, Marilyn. Necessidade de pais, necessidade de mães. Estudos Feministas, v. 3, n. 2, 1985.

TELES, Amelinha. Breve história do feminismo no Brasil. São Paulo: Brasiliense, 1999. Disponível em: www.tj.sc.gov.br. Agravo de instrumento 2002.008939-2.

\section{NOTAS}

- Doutoranda no Programa de Pós-Graduação Interdisciplinar em Ciências Humanas, Universidade Federal de Santa Catarina (DICH/UFSC). Endereço eletrônico: karla_galvao@hotmail.com.

- Doutoranda no Programa de Pós-Graduação em Antropologia Social, Universidade Federal de Santa Catarina (PPGAS/UFSC). Endereço eletrônico: simonebk@yahoo.com.br.

${ }^{1}$ Ainda segundo a autora, houve grande absorção do feminismo marxista pelas feministas oriundas da esquerda radical e pelo movimento de mulheres nas décadas de 70/80. Em grande parte, isto se deu porque o marxismo era uma teoria que auxiliava explicações científicas sobre as origens históricas da discriminação da mulher, apesar de, em outras instâncias, manter as questões de gênero em segundo plano. Amelinha Teles (1999) traz, em Breve história do Feminismo no Brasil, episódios de lutas de classe em que as mulheres impunham o discurso específico das desigualdades de gênero, buscando melhorias tais como o fim do trabalho noturno nas fábricas, contra o controle de tempo para ir ao banheiro, pela criação de equipamentos públicos que permitissem a redução da dupla jornada de trabalho, iguais oportunidades de trabalho, entre outras, apesar de serem minoria nos espaços públicos de enfrentamento e, de terem, na maioria das vezes, os homens como opositores.

${ }^{2}$ Dentre as redes nacionais existentes, faz-se importante trazer aqui as mais representativas das vertentes dos movimentos feministas no Brasil: AArticulação de Mulheres Brasileiras (AMB), a União Brasileira de Mulheres (UBM), a Marcha Mundial de Mulheres e a Rede Feminista de Saúde e Direitos Sexuais e Reprodutivos (Rede Saúde).

${ }^{3}$ Pensando sobre cada um dos atores que compõem esse quadro atual, os núcleos de pesquisas das universidades federais se tornaram um lócus de discussão e produção que retroalimenta as discussões políticas do movimento de mulheres. Além disso, muitas pesquisadoras feministas também participam do movimento organizado. Esses núcleos iniciam com pesquisas sobre mulheres, buscando compreender sua condição em suas relações com o trabalho, com a saúde sexual e reprodutiva, ressaltando a inserção das mesmas nos espaços públicos. 
Algumas reflexões sobre produção da categoria de gênero...

${ }^{4}$ Ao todo, para esse encontro - conferência nacional - foram eleitas duas mil representantes dentre todas as instituições que compõem o campo político feminista brasileiro. Antes, haviam sido eleitas aproximadas 250 representantes para a conferência estadual de Santa Catarina.

${ }^{5}$ Neste caso, que identidades em transformações se constituem? Ou, mais próxima de localizações pós-estruturalistas, que posições de sujeito estão sendo reconfiguradas?

${ }^{6}$ Categoria que deve ser problematizada, seja sob a perspectiva antropológica, seja sob a perspectiva psicológica.

${ }^{7}$ Não mencionamos a paternidade, pois nos voltamos à análise da maternidade e da conseqüente relação de filiação dela decorrente.

${ }^{8}$ Não mantivemos sigilo em relação à identificação da desembargadora, bem como de outros personagens, face ao fato de todos os documentos e falas transcritas dizerem respeito a discursos publicizados.

${ }^{9}$ Mais precisamente pelo Tribunal de Justiça de Santa Catarina (TJSC).

10 “A colocação em família substituta far-se-á mediante guarda, tutela ou adoção, independentemente da situação jurídica da criança ou do adolescente, nos termos desta Lei. Parágrafo $2^{\circ}$. Na apreciação do pedido levar-se-á em conta o grau de parentesco e a relação de afinidade ou de afetividade, a fim de evitar ou minorar as conseqüências decorrentes da medida" (CCB, 2005, p. 883).

${ }^{11}$ Todos os nomes - José, Vera e Marina - são fictícios, pois o processo tramita em segredo de justiça. Uma categoria a ser problematizadas oportunamente.

${ }^{12}$ Sugerimos a leitura de Cláudia Fonseca (1995 e 2004) para melhor compreensão da posição dos pais de classes populares, em diferentes processos, seja de reconhecimento ou negação da paternidade, seja de "adoção à brasileira".

${ }^{13}$ Outra aproximação passível de ser explorada reside entre a culpa imputada a determinados cônjuges que gozam do direito de visitas em processos de separação ou divórcio litigiosos e a homossexualidade de Vera como elemento implícito de perda da guarda.

${ }^{14}$ Para a discussão sobre parentesco e sexualidade, indicamos a leitura de Gayle Rubin (1986) e Maria Luiza Heilborn (2004).

${ }^{15}$ Outra questão que pode ser também explorada é a correlação entre culpa por parte de um dos separandos que fica com o direito de visitas e o estigma de homossexual de Vera. 
${ }^{16}$ Ao escrever o prefácio da obra de Fabiana Marion Splengler (2003), Maria Berenice Dias assim tece suas críticas ao Legislativo:

Sempre foi a justiça que abriu brechas no sistema jurídico positivo para solver questões novas ainda não disciplinadas pela lei. Essa é a grande função criadora da jurisprudência. Não pode o juiz se eximir da obrigação de dar respostas às controvérsias submetidas a julgamento, alegando falta de previsão legislativa. Deve valer-se da analogia, dos costumes e dos princípios gerais do direito, como determinam o artigo $4^{\circ}$ da LICC e o artigo 126 do CPC.

[...] Ao suprir lacunas do sistema legal, o juiz além de servir de modelo para outros magistrados - também acaba forçando o legislativo a "normar o fato, sob pena de restar em mãos do Judiciário, praticamente, a função legiferante substituindo-se ao legislador (p. 12-13).

${ }^{17}$ A nosso ver, algo não percebido quando analisamos o plano legal como se fosse sinônimo de Poder Judiciário - crítica que fazemos à abordagem de Fonseca (2004).

\section{ABSTRACT}

\section{Some Reflections on the Production of the Gender Category in Contexts such as the Feminist Movement and the Judiciary}

Concerning the discussion arisen by modern times (in different social contexts), about the constitution of universal human rights subjects, this paper aims to reflect upon the individual and his search for "citizenship" and "access to justice". Three cases will be analyzed: two conferences on Women's Politics, important in the Brazilian feminist movement. Both concern the relation among women's politics within two non exclusive perspectives: one among women themselves - lesbians, heterosexual, white, black. handicapped - and their tensions related either to individual rights or to collective rights, in a time when quotas are being discussed. The other conference approaches the tension between sex and gender, difference as synonymous with inequality. The third case is about a judgment of guard and responsibility, when maternity of a homosexual woman is restrained, but is allowed to the biological father. At last, we propose the reflection on how, in the two distinct ritual contexts (the Judiciary and the Feminist Movement), the gender category is produced along with the biological binomial - male and female.

Key words: Human rights; gender; feminist movement, the Judiciary. 